\title{
Protein binding interaction of warfarin and acetaminophen in presence of arsenic and of the biological system
}

\author{
Md. Ashraful Alam, Riaz Uddin and Shamsul Haque
}

Department of Pharmacy, Pharmacology and Pharmaceutical Analysis Laboratory, Stamford University Bangladesh, Dhaka, Bangladesh.

\begin{tabular}{|c|c|}
\hline \multicolumn{2}{|l|}{ Article Info } \\
\hline Received: & 8 February 2008 \\
\hline Accepted: & 1 May 2008 \\
\hline Available Online: & 9 May 2008 \\
\hline \multicolumn{2}{|c|}{ DOI: 10.3329/bjp.v3i2.835 } \\
\hline \multicolumn{2}{|c|}{$\begin{array}{l}\text { Cite this article: } \\
\text { Alam MA, Uddin R, Haque S. Protein } \\
\text { binding interaction of warfarin and } \\
\text { acetaminophen in presence of arsenic } \\
\text { and of the biological system. Bangla- } \\
\text { desh J Pharmacol. 2008; 3: 49-54. }\end{array}$} \\
\hline
\end{tabular}

\begin{abstract}
Equilibrium dialysis was used to study in vitro binding of warfarin at physiological $\mathrm{pH}$ and temperature in bovine serum albumin (BSA) along with the increasing concentration of acetaminophen and there interaction with the protein in presence of arsenic. The free fractions were determined by UV spectrophotometric technique. The binding of warfarin to BSA depended on both drug and arsenic concentrations. Free warfarin concentration increased due to addition of acetaminophen (paracetamol) which reduced the binding of warfarin to BSA. Free warfarin concentration also increased accordingly by increasing the concentration of acetaminophen when only the BSA was present. When the binding site was blocked by sufficient amount of arsenic the increment of free concentration of warfarin decreased to a lower extent. This suggests that in presence of arsenic the warfarin being slowly displaced from its high affinity binding site with increasing acetaminophen concentration.
\end{abstract}

\section{Introduction}

The binding of drugs to plasma and tissue protein is an important factor affecting their distribution and rate of metabolism. Pharmacological effect is closely related to the free concentration of drug at its site of action. There are examples of many drug-drug interactions which have been reported to present displacement of the bound drug by a second therapeutic agent. Acidic drugs commonly bind to plasma albumin and concomitantly administered drugs may displace one another from their binding site. Basic drugs may bind to either albumin or a-acid glycoprotein. Despite the ubiquity and severity of drug-drug interactions, this problem is one of the most poorly recognized and poorly understood issues within clinical medicine (Grymonpre et al., 188). The impact of drug-drug interactions on patient safety should be elucidated, and the magnitude of the problem is vast (Einarson et al., 2002). Detection and anticipation of these interactions is a daunting task, given the breadth of pharmacodyna-mic and pharmacokinetic variables with which clini-cians must grapple. NSAIDs have high protein binding that may represent displacement of bound drugs espe-cially those bound to albumin (Amitava and Timothy, 1996). Mefenamic acid can displace warfarin from its binding sites (Zahra et al., 2006). Acetaminophen is the preferred analgesic over aspirin and a non-steroidal anti-inflammatory drug for patients treated with warfarin because it lacks the potential to induce gastrointestinal bleeding and has no anti-platelet activity (Chan, 1995). Evidence suggests, however, that oral anticoagulation therapy with vitamin $\mathrm{K}$ antagonists, such as warfarin, may be potentiated by acetaminophen (Antlitz et al., 1968).

Moreover, epidemiological studies have revealed that chronic arsenic exposure in many countries caused the increased risk of mortality associated with cardiovascular disease (Engel et al., 1994), but a plausible 


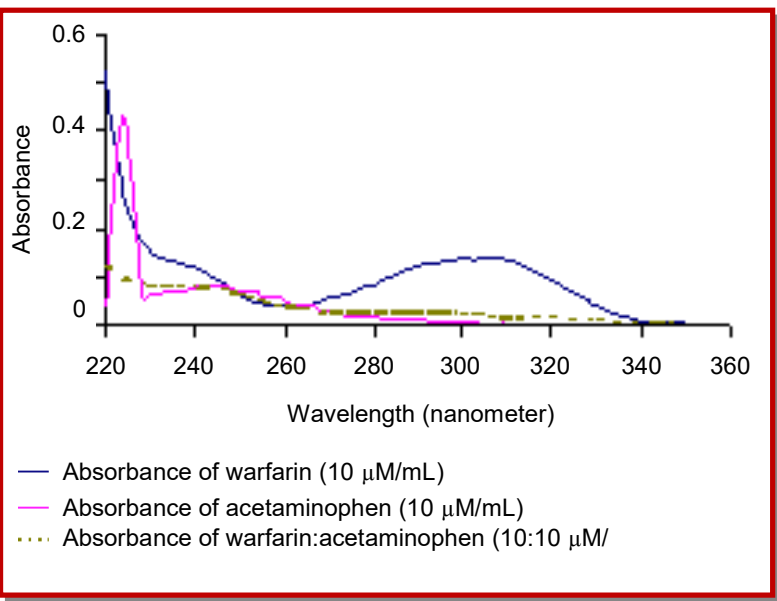

Figure 1: Corresponding zero order absorption spectrum of warfarin $(10 \mu \mathrm{M} / \mathrm{mL})$; acetaminophen $(10 \mu \mathrm{M} / \mathrm{mL})$ and warfarin:acetaminophen $(10: 10 \mu \mathrm{M} / \mathrm{mL})$

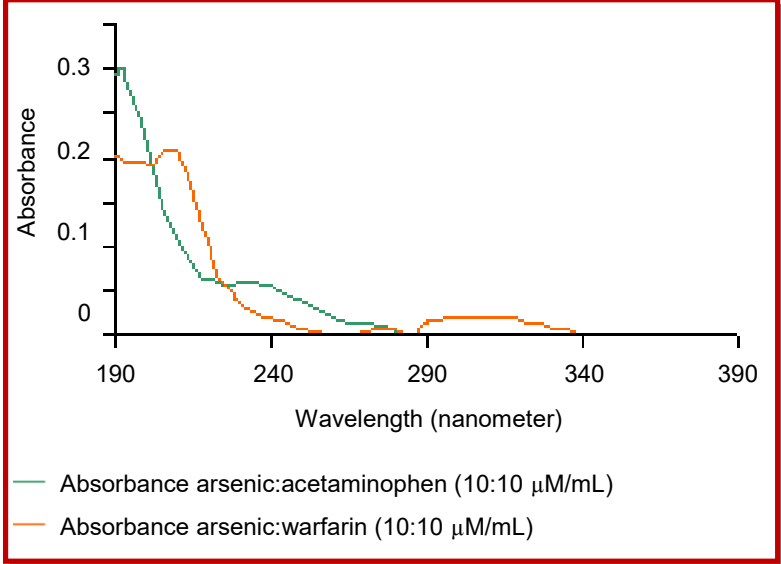

Figure 2: Corresponding zero order absorption spectrum of arsenic:acetaminophen $(10: 10 \mu \mathrm{M} / \mathrm{mL})$ and arsenic:warfarin $(10: 10 \mu \mathrm{M} / \mathrm{mL})$

explanation for the development of arsenic-induced cardiovascular disease has not been previously examined. Cardiovascular effects in humans drinking arsenic-contaminated water include blackfoot disease (resulting from gangrene caused by obstruction of peripheral blood vessels), atherosclerosis, cerebrovascular diseases, and ischemic heart diseases (Tseng, 1977; Rahman et al., 1999). These diseases have been clinically associated with abnormal platelet activity and thrombosis and, as a consequence, new drugs have been developed to therapeutically control platelet action and thrombosis (Hollopeter et al., 2001).

In view of the above consideration we conducted an in vitro investigation on displacement interaction of warfarin in presence of acetaminophen and arsenic. Protein binding studies are carried out with several methods among which equilibrium dialysis is a routine method and was performed in our laboratory.

\section{Materials and Methods}

\section{Drug and reagents used in the experiment}

Acetaminophen (General Pharmaceutical Ltd., Bangladesh), warfarin (Incepta Pharmaceuticals Ltd., Bangladesh), disodium hydrogen phosphate $\left(\mathrm{Na}_{2} \mathrm{HPO}_{4}\right)$, potassium dihydrogen phosphate $\left(\mathrm{KH}_{2} \mathrm{PO}_{4}\right)$, cellulose nitrate membrane (Medicell International Ltd. Liverpool Road, London; mol. Wt. 1200 daltons), bovine serum albumin (BSA) (fatty acid free, fraction V, Mr. 66,500 from Sigma Chemical Ltd.), arsenic trioxide $\left(\mathrm{As}_{2} \mathrm{O}_{3}\right)$.

\section{Instrument used}

$\mathrm{pH}$ meter (HANNA Microprocessor $\mathrm{pH}$ Meter, Portugal), HACH-4000 UV/VIS spectrophotometer (USA), metabolic shaking incubator (Clifton Shaking Bath, Nical electro Ltd., England), microsyringe (well. Liang. Jin. Yang.q.I., China.)

\section{Standard curve preparation}

Standard curve was prepared by using the various concentrations and their corresponding absorbance at $\mathrm{pH}$ 7.4. UV spectrophotometric scanning of the drugs acetaminophen and warfarin showed maximum absorbance of the UV light at 246 and $306 \mathrm{~nm}$ respectively. Acetaminophen had found linearity at a concentration of $10-80 \mu \mathrm{M} / \mathrm{mL}$ with a confidence level of 0.9967 at $\mathrm{pH}$ 7.4 with linear equation $(Y=0.0107 \mathrm{X})$. Similar standard curve had also been prepared for warfarin having linear equation $\mathrm{Y}=0.1264 \mathrm{X}+0.0161$ and calculated the concentration of those drugs using corresponding liner equation. Zero order absorption spectrum of the various systems containing warfarin $(10 \mu \mathrm{M})$, acetaminophen $(10 \mu \mathrm{M})$, acetaminophen: warfarin $(10: 10 \mu \mathrm{M})$, arsenic:warfarin (10:10 $\mu \mathrm{M})$, arsenic:acetaminophen $(10: 10 \mu \mathrm{M})$ was plotted in the Figure 1 and 2 using HACH 4000 UV/VIS spectrophotometer (USA).

\section{Effect of acetaminophen on warfarin binding to BSA in presence of arsenic}

Three milliliter of previously prepared $20 \mathrm{mM}$ BSA solution was taken in each of seven cleaned and dried test tubes. $12 \mathrm{~mL}$ of $1^{\prime} 10^{-2} \mathrm{M}$ arsenic trioxide solution was taken in each of six cleaned and dried test tubes. So that final ratio between protein and arsenic trioxide was 1:2 (20:40 mM) in each of six test tubes. Then the site II is sufficiently blocked by arsenic trioxide. The seventh test tube containing only BSA solution was marked as blank. After that warfarin was added in 6 out of 7 test tubes so that protein, arsenic and warfarin was 1:2:1 (20:40 mM: $20 \mathrm{M}$ ). Acetaminophen was added with an increasing concentration in to five out of six test tubes containing 1:2:1 mixture of protein-arsenic tri oxidewarfarin to make the final ratio of protein, arsenic, warfarin and acetaminophen 1:2:1:0, 1:2:1:1, 1:2:1:2, 


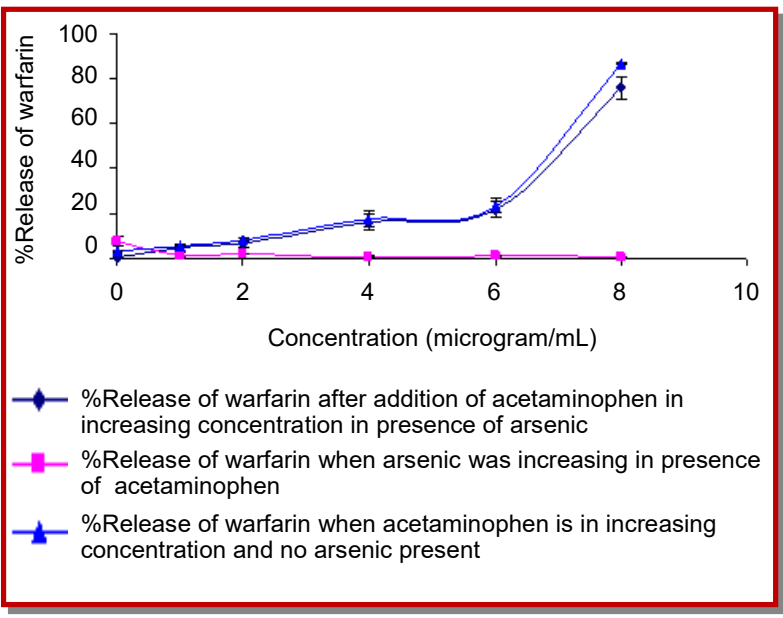

Figure 3: \%Release of warfarin from protein binding site in presence of acetaminophen and arsenic

1:2:1:4, 1:2:1:6 and 1:2:1:8. Acetaminophen was not added to one test tube. The solution mixture were then properly mixed and allowed to stand for $15 \mathrm{~min}$ for the confirmation of maximum binding to BSA. After that the solution was pipetted out and poured in to seven different semi permeable membrane tubes. Two end of the membrane tube were clipped and was ensured that there was no leakage. The tubes containing drug mixture were immerged into seven $50 \mathrm{~mL}$ conical flasks containing phosphate buffer solution of $\mathrm{pH} 7.4$ and shaked continuously for six hours uninterruptly to complete the dialysis. At the end of dialysis, samples were collected from each flask. The free concentrations of warfarin were measured by a UV spectrophotometer at a wavelength of $306 \mathrm{~nm}(\mathrm{BP})$.

Effect of acetaminophen on warfarin binding to BSA in absence of arsenic

To perform the experiment the previously described procedure has been followed successively in absence of arsenic. Acetaminophen was added with an increasing concentration into five out of six test tubes containing 1:1 mixture of protein:warfarin to make the final ratio of protein, warfarin and acetaminophen 1:1:0, 1:1:1, 1:1:2, 1:1:4, 1:1:6 and 1:1:8. Acetaminophen was not added to one test tube. That is acetaminophen was not present into the first test tube which contained only proteinwarfarin mixture (1:1) and the rest of the experiment was done as described above using phosphate buffer solution of $\mathrm{pH}$ 7.4. At the end of dialysis, samples were collected from each flask. The free concentrations of warfarin were measured by a UV spectrophotometer at a wavelength of $306 \mathrm{~nm}$ (BP).

\section{Effect of arsenic on warfarin binding to BSA in presence of acetaminophen}

To perform the experiment the previously described procedure has been followed successively. Arsenic was added with an increasing concentration in to five out of six test tubes containing 1:1:1 mixture of proteinwarfarin-acetaminophen to make the final ratio of protein, warfarin, acetaminophen and arsenic 1:1:1:0, $1: 1: 1: 1,1: 1: 1: 2,1: 1: 1: 4,1: 1: 1: 6$ and 1:1:1:8. Arsenic was not added to one test tube. That is arsenic was not present into the first test tube which contained only protein:warfarin:acetaminophen mixture (1:1:1) and the rest of the experiment was done as described above using phosphate buffer solution of $\mathrm{pH}$ 7.4. At the end of dialysis, samples were collected from each flask. The free concentrations of warfarin were measured by a UV spectrophotometer at a wavelength of $306 \mathrm{~nm}$ (BP).

\section{Results and Discussions}

Chronic ingestion of arsenic contaminated drinking water is the major pathway posing potential risk to human health (Bagla and Kaiser, 1996). Since the early 1990s, in Bangladesh alone, arsenic exposure has caused more than 7,000 deaths and uncounted thousands show symptoms of long-term arsenic poisoning (Masibay, 2000). Significant portions of world populations are exposed to low to moderate levels of arsenic of parts per billion to hundreds of parts per billion. As a consequence, the World Health Organization and U.S. environmental health agencies, such as the Environmental Protection Agency made arsenic their highest priority (Goering et al., 1999). Recently, the WHO established an acceptable level of $10 \mathrm{ppb}$ for arsenic in drinking water (Lok, 2001). The EPA also recently proposed to reduce its drinking water standard from 50 to $10 \mathrm{ppb}$; however, this newly proposed maximum contaminant level is now being reevaluated for scientific merit (Kaiser, 2001). Arsenic ingestion may also aggravate the platelet aggregation and may cause induce vascular diseases (Lee et al., 2002). The activation and resulting aggregation of platelets are believed to be important events in both hemostasis and the pathogenesis of various vascular diseases due to thrombus formation (Marcus and Safier, 1993). Platelet aggregation is initiated by physiological agonists, such as thrombin, and hemodynamic factors, such as shear stress (Clemetson, 1995). Under normal physiological conditions, haemostatic balance by platelets is strictly regulated between pro-aggregation (activation of platelets) and anti-aggregation (inhibition of platelet activation) activity.

However, co-prescribing interacting medications can result in serious patient consequences, particularly in patients who receive warfarin, because of warfarin's narrow therapeutic index (Greenblatt and von Moltke, 2005). Combined therapeutic use of warfarin and acetaminophen is very common, and a clinically significant drug interaction is a debated matter. Insufficient data have been acquired on this interaction in 
controlled experiments using INR determinations to monitor the level of anticoagulation. Many drugs routinely co-administered with warfarin interact by inhibition or induction of hepatic cytochrome $\mathrm{P}_{450}$ (CYP) oxidative enzymes (Buckley and Dawson, 1992).

During concurrent administration of warfarin and acetaminophen, site to site displacement take place and acetaminophen displaced warfarin from its binding sites more slowly (i.e. induces small free concentration). But in the presence of probe arsenic increment of acetaminophen to BSA, free concentration of warfarin was less prominent. This displacement may be due to reduce the binding site of warfarin and increasing the free drug concentration, whereas in the presence of arsenic, warfarin may form complex with arsenic or arsenic may increases the binding affinity to its sites or arsenic may form complex to BSA. As observed in Figure 3, during concurrent administration, acetaminophen displaced warfarin from its high affinity binding site I. Thus free concentration of warfarin increased from $3.2 \pm 0.6$ and $0.8 \pm 0.1 \%$ to $86.8 \pm 0.5$ and $75.8 \pm$ $4.9 \%$ in absence and presence of site II probe (arsenic) respectively.

It has been proposed that competition for $\mathrm{CYP}_{1} \mathrm{~A}_{2}$ between acetaminophen and R-warfarin causes a clinically significant drug interaction (Lehmann et al., 2000). Warfarin is highly protein-bound, and despite its low tendency to bind to plasma proteins, acetaminophen has the potential to increase the unbound fraction of warfarin (Forrest et al., 1982). An increased concentration of unbound warfarin can be expected to increase inhibition of vitamin K-dependent factors, as it is unbound warfarin that binds to the vitamin $\mathrm{K}$ epoxide reductase enzyme in the liver (Thijssen et al., 1987).

Our findings may be important when considering prior work that supports the potential severity of warfarin interactions. Drug interactions are the most common factor associated with a critically high INR (Panneerselvam et al., 1998) and an increased risk of bleeding (Van der Meer et al., 1993). Acetaminophen has been reported by Hylek et al to be an unrecognized hazard for warfarin takers- as little as 1,300 mg/day for 7 days increased by 10 -fold the odds of an INR greater than 6 . However, it is important to note that the clinical significance of the acetaminophen-warfarin interaction is not without controversy. The mechanism of this interaction has only recently been elucidated (Thijssen et al., 2004) and likely results from the independent inhibitory effect of an acetaminophen metabolite on enzymes of the vitamin K cycle. Although several case reports and controlled studies have reported that acetaminophen potentiates the anticoagulant effect of warfarin (Hylek et al., 1998), others have not found a clinically relevant interaction (Fattinger et al., 2002). NSAIDs such as mefenamic acid (Holmes, 1966) etodolac (Ermer et al., 1994; ibuprofen (Penner and
Abbrecht, 1975) and tenidap (Apseloff et al., 1995) may also displace coumarin anticoagulants from protein binding sites.

Acetaminophen was associated with an increased hypoprothrombinemic effect of warfarin. This interacttion is proposed to be due to inhibition of its metabolism and interference with formation of clotting factors. Gingival bleeding and hematuria were observed in case reports when paracetamol is given with warfarin (Hylek et al., 1998). However, due to lack of a safer alternative, paracetamol is still the analgesic and antipyretic of choice in patients receiving warfarin therapy, as long as excessive amounts and prolonged administration are avoided (Shek et al., 1999). A combination of paracetamol and codeine has enhanced warfarin activity (Bartle and Blakely, 1991).

Thus it can be suggested that acetaminophen displaced warfarin from its binding site I and at the same time a sufficient portion of the free drug might have bound to site II or increase the free drug concentration in plasma. The release pattern of warfarin was somewhat lower in presence of arsenic alone in increasing concentration in presence of acetaminophen and the \%release of drug was $7.8 \pm 2.1$ to $0.8 \pm 0.2 \%$ after increasing the arsenic concentration from its initial value of 10 to $80 \mu \mathrm{M}$. This result is quite an interesting finding considering our previous work (Uddin et al., 2004).

Considering the above result and discussion it would demand extensive research for the safety of those patients who are taking warfarin along with acetaminophen in a locality where arsenic free drinking water cannot be avoided due to the lack of better alternatives.

\section{Financial Support}

Self-funded

\section{Ethical Issue}

The study was approved by the Ethical Committee of the Stamford University Bangladesh

\section{Conflict of Interest}

Authors declare no conflict of interest

\section{References}

Amitava D, Timothy GT. In vitro displacement of phenytoin from protein binding by non-steroidal anti-inflammatory drugs tolmetin, ibuprofen and naproxen in normal and uremic sera. TDM. 1996; 18: 97-99.

Antlitz AM, Mead JA, Tolentino MA. Potentiation of oral 
anticoagulant therapy by acetaminophen. Curr Ther Res. 1968; 10: 501-06.

Apseloff G, Wilner KD, Gerber N. Effect of tenidap sodium on the pharmacodynamics and plasma protein binding of warfarin in healthy volunteers. Br J Clin Pharmacol. 1995; 39: 29S-33S.

Bagla P, Kaiser J. India's spreading health crisis draws global arsenic experts. Science 1996; 274: 174-75. http://dx.doi.org/10.1126/science.274.5285.174

Buckley NA, Dawson AH. Drug interactions with warfarin. Med J Australia. 1992; 157: 479-83.

Chan TY. Adverse interactions between warfarin and nonsteroidal anti-inflammatory drugs: Mechanisms, clinical significance, and avoidance. Ann Pharmacother. 1995; 29: 1274-83.

Clemetson KJ. Platelet activation: Signal transduction via membrane receptors. Thromb. Haemostasis 1995; 74: 111-16.

Einarson TR, Metge CJ, Iskedjian M, Mukherjee J. An examination of the effect of cytochrome P450 drug interactions of hydroxymethylglutaryl- coenzyme A reductase inhibitors on health care utilization: A Canadian population-based study. Clin Ther. 2002; 24: 2126-36. http:// dx.doi.org/10.1016/S0149-2918(02)80102-3

Engel RR, Hopenhayn-Rich C, Receveur O, Smith AH. Vascular effects of chronic arsenic exposure: A review. Epidemiol Rev. 1994; 16: 184-209.

Ermer JC, Hicks DR, Wheeler SC et al. Concomitant etodolac affects neither the unbound clearance nor the pharmacologic effect of warfarin. Clin Pharmacol Ther. 1994; 55: 305-16.

Forrest JA, Clements JA, Prescott LF. Clinical pharmacokinetics of paracetamol. Clin Pharmacokin. 1982; 7: 93-107.

Gadisseur AP, van der Meer FJ, Rosendaal FR. Sustained intake of paracetamol (acetaminophen) during oral anticoagulant therapy with coumarins does not cause clinically important INR changes: A randomized doubleblind clinical trial. J Thromb Haemost. 2003; 1: 714-17. http:/ / dx.doi.org/10.1046/j.1538-7836.2003.00135.x

Goering PL, Aposhian HV, Mass MJ, Cebrian M, Beck BD, Waalkes MP. The enigma of arsenic carcinogenesis: Role of metabolism. Toxicol Sci. 1999; 49: 5-14. http:// dx.doi.org/10.1093/toxsci/49.1.5

Greenblatt DJ, von Moltke LL. Interaction of warfarin with drugs, natural substances, and foods. J Clin Pharmacol. 2005; 45: 127-32. http://dx.doi.org/10.1177/0091270004271404

Grymonpre RE, Mitenko PA, Sitar DS, Aoki FY, Montgomery PR: Drug-associated hospital admissions in older medical patients. J Am Geriatr Soc. 1988; 36: 1092-98.

Hertz-Picciotto I, Arrighi HM, Hu SW. Does arsenic exposure increase the risk for circulatory disease? Am J Epidemiol. 2000; 151: 174-81.

Hollopeter G, Jantzen HM, Vincent D, Li G, England L, Ramakrishnan V, Yang RB, Nurden P, Nurden A, Julius D, Conley PB. Identification of the platelet ADP receptor targeted by antithrombotic drugs. Nature 2001; 409: 202-07. http://dx.doi.org/10.1038/35051599

Holmes EL. Experimental observations on flufenamic, mefenamic, and meclofenamic acids. IV. Toleration by normal human subjects. Ann Phys Med. 1966; 9 (Suppl): 3649.

Hylek EM, Heiman H, Skates SJ, Sheehan MA, Singer DE. Acetaminophen and other risk factors for excessive warfarin anticoagulation. JAMA. 1998; 279: 657-62. http:// dx.doi.org/10.1001/jama.279.9.657

Kaiser J. Toxicology: Science only one part of arsenic standards. Science 2001; 291: 2533. http://dx.doi.org/10.1126/ science.291.5513.2533a

Lee MY, Bae ON, Chung SM, Kang KT, Lee JY, Chung JH. Enhancement of platelet aggregation and thrombus formation by arsenic in drinking water: A contributing factor to cardiovascular disease. Toxicol Appl Pharmacol. 2002; 179: 83-88. http://dx.doi.org/10.1006/ taap.2001.9356

Lehmann DF. Enzymatic shunting: Resolving the acetaminophen-warfarin controversy. Pharmacotherapy 2000; 20: 146568. http:/ / dx.doi.org/10.1592/ phco.20.19.1464.34860

Lok C. Plans to reduce acceptable arsenic limit put on hold. Nature 2001; 410: 503-03. doi:10.1038/35069212

Marcus AJ, Safier LB. Thromboregulation: Multicellular modulation of platelet reactivity in haemostasis and thrombosis. FASEB J. 1993; 7: 516-22.

Masibay K. Drinking without harm. Sci Am. 2000; 283: 22.

Panneerselvam S, Baglin C, Lefort W, Baglin T. Analysis of risk factors for overanticoagulation in patients receiving longterm warfarin. Br J Haematol. 1998; 103: 422-24. http:// dx.doi.org/10.1046/j.1365-2141.1998.00988.x

Rahman M, Tondel M, Ahmad SA, Chowdhury IA, Faruquee $\mathrm{MH}$, Axelson O. Hypertension and arsenic exposure in Bangladesh. Hypertension 1999; 33: 74-78.

Schulman S, Henriksson K. Interaction of ibuprofen and warfarin on primary haemostasis. Br J Rheumatol. 1989; 28: 46-49. http://dx.doi.org/10.1093/rheumatology/28.1.46

Shek KLA, Chan LN, Nutescu E. Warfarin acetaminophen drug interaction revisited. Pharmacotherapy 1999; 19: 115358. http:/ / dx.doi.org/10.1592/ phco.19.15.1153.30584

Thijssen HH, Soute BA, Vervoort LM, Claessens JG. Paracetamol (acetaminophen) warfarin interaction: NAPQI, the toxic metabolite of paracetamol, is an inhibitor of enzymes in the vitamin K cycle. Thromb Haemost. 2004; 92: 797-802.

Thijssen HHW, Baars LGM. Hepatic uptake and storage of warfarin: The relationship with the target enzyme vitamin $\mathrm{K}$ 2, 3-epoxide reductase. J Pharmacol Exp Ther. 1987; 243: 1082 -88 .

Tseng WP. Effects and dose-response relationships of skin cancer and blackfoot disease with arsenic. Environ Health Perspect. 1977; 19: 109-19. http:// dx.doi.org/10.2307/3428460 
Uddin SJ, Shilpi JA, Murshid GMM, Rahman AA, Sarder MM, Alam MA. Determination of the binding sites of arsenic on bovine serum albumin using warfarin (site I specific probe) and diazepam (site II specific probe). J Biol Sci. 2004; 4: 60912.

van der Meer FJ, Rosendaal FR, Vandenbroucke JP, Briet E. Bleeding complications in oral anticoagulant therapy: An analysis of risk factors. Arch Intern Med. 1993; 153: 1557-62. http://dx.doi.org/10.1001/archinte.153.13.1557

Zahra R, Ahmad R, Asghar MSA, Ali A, Soghra K. A study of the interaction between ropranolol and NSAIDS in protein binding by gel filtration method. Indian J Clin Biochem. 2006; 21: 121-25. 